\title{
The relationship between personality types and perceived stress in parturient women referred to hospitals affiliated with the Shiraz University of Medical Sciences
}

\author{
SAHAR PARVIZI ${ }^{1, B-F}$, ZAHRA YAZDANPANAHI 2, A, F , FATEMEH RAHMANIAN ${ }^{2, A, F}$, \\ MARZIEH AKBARZADEH ${ }^{3, A, ~ c-F}$ \\ ORCID ID: 0000-0002-4491-2437
${ }^{1}$ Department of Midwifery, School of Nursing and Midwifery, Shiraz University of Medical Sciences, Shiraz, Iran ${ }^{2}$ Community Based Psychiatric Care Research Centre, Department of Midwifery, School of Nursing and Midwifery, Shiraz University of Medical Sciences, Shiraz, Iran
${ }^{3}$ Maternal-Fetal Medicine Research Centre, Department of Midwifery, School of Nursing and Midwifery, Shiraz University of Medical Sciences, Shiraz, Iran

A - Study Design, B - Data Collection, C - Statistical Analysis, D - Data Interpretation, E - Manuscript Preparation, F - Literature Search, G - Funds Collection

Summary Background. Pregnancy is one of the most sensitive periods in a woman's life, causing great changes and emotional instability. Pregnancy, apart from the pleasure of being a mother, is the most stressful period of the life of women.

Objectives. This study aimed to investigate the relationship between mothers' personality types and their perceived stress.

Material and methods. This cross-sectional descriptive-analytic study was conducted on 210 eligible mothers in three hospitals affiliated with the Shiraz University of Medical Sciences. Personality and Perceived Stress Questionnaires were completed by the mothers. Data analysis was performed with Pearson and Spearman statistical tests, using SPSS software (version 22).

Results. The highest score of the personality type belonged to the conscientiousness, with an average score of $39.68 \pm 6.09$. The highest frequency was also related to conscientiousness personality type $(48.1 \%)$. Mothers in the study had a moderate perceived stress level, with a mean score of 26.98. Using the Pearson correlation test, we found there was a significant positive relationship between the two variables of neuroticism and perceived stress $(r=0.149, p=0.031)$. There was also a significant relationship between openness to experience and perceived stress $(r=0.265, p=0.001)$.

Conclusions. According to the results, personality types are related to the level of perceived stress in mothers, and maternal stress can be predicted through personality traits. Therefore, identifying the personality types, training of mothers and holding psychotherapy sessions can be very important.

Key words: personality, pregnant women, stress physiological.

Parvizi S, Yazdanpanahi Z, Rahmanian F, Akbarzadeh M. The relationship between personality types and perceived stress in parturient women referred to hospitals affiliated with the Shiraz University of Medical Sciences. Fam Med Prim Care Rev 2019; 21(4): 349-354, doi: https://doi.org/10.5114/fmpcr.2019.90166.

\section{Background}

Stress is a nonspecific response caused by various stressors in the organism, which threatens the individual's physical and psychological well-being, and anxiety is one of its complications $[1,2]$. Pregnancy causes great changes and emotional instability, and apart from the pleasure of being a mother, it is the most stressful period in the life of women. Stress in pregnancy appears as a form of discomfort and irritability, often associated with the autonomic stimulus of the nervous system [3]. In pregnancy, hormonal and physical changes, changes in personal identity and interpersonal relationships may cause stress and affect the health of the mother $[3,4]$.

Maternal stress in pregnancy leads to reduced foetal weight, abortion, preterm labour, increased foetal abnormalities and infant mortality [3]. Among the complications of a mother's postpartum stress are postpartum depression, mood disorders, hypertension and episiotomy infection [5]. Unsolved emotional problems during this time may have a long-lasting negative influence on the family, the baby and the woman herself [6].

The degree of perceived stress depends on how an individual perceives the degree of threatening situations [7]. Many researchers believe that the existence of individual differences and different personality traits influence an individual's response to stress [8]. Personality factors are effective in the selection of coping strategies that result from the appropriate psychological and physical changes [3] and lead to different responses by people in the same situation. One of these situations is the delivery of a child by pregnant women. Some women handle the issue of child delivery through natural stress, but others have severe anxiety and a fear of delivery. Sometimes, due to this fear, a caesarean section is used for childbirth rather than a normal delivery. Therefore, the severity of fear in pregnant women is also related to personality factors [9]. According to Matinnia et al., perceived stress is one of the psychological factors involved in the decision of primigravida women for delivery by an elective caesarean section [10]. In Harville's study conducted in the United States, neuroticism was less related to lower birth weight and gestational age [11].

Today, the big five-factor personality model is widely used. According to this model, people are divided into five categories of neuroticism, extraversion, openness to experience, conscientiousness and agreeableness [12]. 
Pregnancy and delivery are considered as a crisis in women's lives, and the stable mental health of women is a guarantee for the health of the family and the child who will soon be born. Therefore, it is important to be aware of the personality characteristics of mothers in this period and the relationship that it may have with stress. Therefore, the purpose of this study was to investigate the relationship between personality types and perceived stress in mothers.

\section{Material and methods}

\section{Study design}

This cross-sectional descriptive-analytic study was conducted on 210 eligible mothers in three hospitals affiliated with the Shiraz University of Medical Sciences.

\section{Setting}

The research setting was the maternity ward of Hazrat Zeinab, Hafez and Shooshtari Hospitals in Shiraz. Therefore, the researcher referred to the mentioned centres at the time of the study and began a sampling of the mothers (including 105 nulliparous women and 105 multiparous women) who were eligible in terms of the study inclusion criteria. At first, written consent, a demographic questionnaire, personality type and perceived stress questionnaires were filled out by mothers in the recovery room of the maternity ward.

\section{Participants}

210 parturient women participated in the study, which included 105 nulliparous women and 105 multiparous women. The inclusion criteria were the patient's willingness for participation in the study, no high risk pregnancy (multiple pregnancies, problems with placenta and foetus, etc.), parturient women with a gestational age between 37-42 weeks [3], no internal diseases and no surgical operation on the mother and foetus, no current and past mental illnesses, no use of psychosocial drugs, a wanted pregnancy, no poor midwifery history of mothers and no use of fertility methods by the mother. The study exclusion criteria included lack of willingness to continue participation in the study and a report of physical or mental illness during the study. Random sampling method of all three centres was in compliance with proportional allocation.

\section{Variables}

Personality type and stress level of participants were assessed.

\section{Data sources/measurement}

To measure the personality type of individuals, the Goldberg big five personality questionnaire was used, which consisted of 50 items. This questionnaire was used to investigate and evaluate five personality types in the individuals. The scoring of the questionnaire was based on the Likert scale. In this study, the scores were: mostly false $=1$, somewhat false $=2$, not true and not false $=3$, somewhat true $=4$, mostly true $=5$. Five personality components of extraversion, agreeableness, conscientiousness, neuroticism and openness to experience, each one with 10 items, were measured in the questionnaire. The higher score in each component represents the dominant character in the person. Some questions were also rated in reverse [13]. In Sharifzadeh's study, the validity of the personality questionnaire was reported desirable. The reliability of the questionnaire using Cronbach's alpha in Ghorbani's et al. study was reported above $90 \%[14,15]$. The validity of Sharifzadeh's study and the reliability of Ghorbani's et al. study were considered as the basis of the present study.
To measure perceived stress, we used the perceived stress questionnaire of Cohen et al. This scale had 14 items with the four-point Likert scale (ranging from never to too much), and a score was allocated from 0 to 4 for each item. In this study, the scores were: zero $=0$, low $=1$, average $=2$, high $=3$, very high $=4$. The minimum possible score was 0 and the maximum was 56 [16]. For data analysis, the obtained scores were summed up and judged accordingly: a score between 0-18 represented a low level of perceived stress, a score between 18-36 represented an average level, and a score above 36 represented a high level. The validity and reliability of this questionnaire were confirmed in a study carried out by Saadat et al., and the reliability of the questionnaire according to Cronbach's alpha was above $7 \%$ [17]. The validity and reliability of the study by Saadat et al. were used as the basis of this study.

\section{Study size}

The sample size, using the related article [18] and the sample size formula of $n=\frac{\left(z_{1-\frac{\alpha}{2}}+z_{1}-\beta\right)^{2}}{d^{2}}$, was estimated to be

175 . Considering the probability of its reduction by $20 \%$, it increased to 210 .

\section{Statistical methods}

For data analysis, descriptive statistics, including frequency, frequency percentage, mean and standard deviation, were used to describe the variables of personality type and perceived stress. Moreover, inferential statistics, including Pearson correlation coefficient test, were used to examine the relationship between the personality type and perceived stress using SPSS, version 22. The level of significance was $p<0.05$.

\section{Ethical consideration}

This research project was approved by the local Ethics Committee of Shiraz University of Medical Sciences (research proposal no: 1396-01-08-15341, ethic number: IR.SUMS.REC.1396. S663). Besides, informed consent was taken from participants. The participants were assured of the confidentiality of all their personal information.

\section{Results}

\section{Descriptive data}

The mean age of the participants in this study was 27.11 years, with a range of $17-42$ years. $30(14.3 \%)$ were less than 20 years old, and 19 (9\%) were more than 36 years old. 93.8\% of the mothers were housewives, and $6.2 \%$ of them were employed. In terms of educational level, $3.3 \%$ of them were illiterate, $6.7 \%$ had elementary education, $29 \%$ had secondary education, $38.6 \%$ had diplomas, and $22.4 \%$ had higher education at a university level.

\section{Outcome data}

Among the 210 individuals in the sample group, the mean score of extraversion was 31.02 , with a standard deviation of 6.3; agreeableness was 38.82 , with a standard deviation of 5.25; conscientiousness was 39.68 , with a standard deviation of 6.0.09; the mean score of neuroticism was 31.47 , with a standard deviation of 5.06; openness to experience was 33.98, with a standard deviation of 5.09 (Table 1). Among the 210 individuals in the sample group, 5 individuals (2.4\%) were extraversion, 57 individuals (27.1\%) were agreeable, 101 individuals (48.1\%) were conscientiousness, 11 individuals (5.2\%) were neurotic, 13 
individuals (6.2\%) were open to experience, 6 individuals (2.9\%) were agreeable and open to experience, 15 individuals (7.1\%) were agreeable and conscientious, 1 individual $(0.5 \%)$ was agreeable and neurotic, and 1 person (0.5\%) was an extravert (Table 2). Out of 210 people, the average perceived stress was 26.98 , with a standard deviation of 56.5 . Out of 210 individuals in the sample group, 29 people (13.8\%) had low perceived stress, 164 (78.1\%) were moderate, and 17 (8.1\%) had high perceived stress (Table 3).

\begin{tabular}{|c|c|c|c|c|c|}
\hline Variable & Number & $\begin{array}{l}\text { Mini- } \\
\text { mum }\end{array}$ & $\begin{array}{l}\text { Maxi- } \\
\text { mum }\end{array}$ & Mean & $\begin{array}{l}\text { Standard } \\
\text { deviation }\end{array}$ \\
\hline Extraversion & 210 & 14 & 47 & 31.02 & 6.30 \\
\hline $\begin{array}{l}\text { Agreeable- } \\
\text { ness }\end{array}$ & 210 & 22 & 50 & 38.82 & 5.02 \\
\hline \begin{tabular}{|l} 
Conscien- \\
tiousness
\end{tabular} & 210 & 20 & 50 & 39.68 & 6.09 \\
\hline Neuroticism & 210 & 17 & 45 & 31.47 & 5.06 \\
\hline $\begin{array}{l}\text { Openness to } \\
\text { experience }\end{array}$ & 210 & 12 & 45 & 33.98 & 5.09 \\
\hline
\end{tabular}

\begin{tabular}{|c|c|c|}
\hline Variable & Frequency & $\%$ \\
\hline Extraversion & 5 & 2.4 \\
\hline Agreeableness & 57 & 27.1 \\
\hline Conscientiousness & 101 & 48.1 \\
\hline Neuroticism & 11 & 5.2 \\
\hline Openness to experience & 13 & 6.2 \\
\hline Openness to experience, agreeableness & 6 & 2.9 \\
\hline $\begin{array}{l}\text { Agreeableness, } \\
\text { conscientiousness }\end{array}$ & 15 & 7.1 \\
\hline Agreeableness, neuroticism & 1 & 0.5 \\
\hline Extraversion, conscientiousness & 1 & 0.5 \\
\hline Total & 210 & 100 \\
\hline
\end{tabular}

\begin{tabular}{|c|c|c|c|c|}
\hline Variable & Frequency & Percentage & Mean & $\begin{array}{l}\text { Standard } \\
\text { deviation }\end{array}$ \\
\hline Low & 29 & 13.8 & \multirow{4}{*}{26.98} & \multirow{4}{*}{7.56} \\
\hline Moderate & 164 & 78.1 & & \\
\hline High & 17 & 8.1 & & \\
\hline Total & 210 & 100 & & \\
\hline
\end{tabular}

\section{Main results}

Based on the result of Pearson's correlation test, the correlation between the two variables of neuroticism and perceived stress was $r=0.149$, with a significance level of $p=0.031$. Therefore, there was a significant positive relationship between the two variables of neuroticism and perceived stress. The correlation between the two variables of openness to experience and perceived stress was 0.245 , with a significance level of 0.001 , which was 0.05 lower than the assumed error in the study. Therefore, there was a significant positive relationship between the two variables of openness to experience and perceived stress (Table 4).

\begin{tabular}{|c|c|c|c|}
\hline Personality types & $\begin{array}{l}\text { Correlation } \\
\text { coefficient }\end{array}$ & Number & $\begin{array}{l}\text { Significance } \\
\text { level }\end{array}$ \\
\hline Extraversion & 0.081 & \multirow{5}{*}{210} & 0.245 \\
\hline Agreeableness & 0.069 & & 0.321 \\
\hline Conscientiousness & 0.01 & & 0.881 \\
\hline Neuroticism & 0.149 & & 0.031 \\
\hline $\begin{array}{l}\text { Openness to expe- } \\
\text { rience }\end{array}$ & 0.265 & & 0.0001 \\
\hline
\end{tabular}

\section{Discussion}

\section{Key results}

The highest score of personality type belonged to conscientiousness, with a mean score of $39.68 \pm 6.09$. The highest frequency was also assigned to conscientiousness (48.1\%), followed by agreeableness (27.1\%). In the study of Varshoei Jaghargh and Haji Alizadeh in Bandar Abbas, with the aim of determining the predictive factors of the fear of delivery, the personality trait of conscientiousness had the highest mean value [19]. The findings of Berg's et al. study, performed in England, showed that conscientiousness was strongly linked to the implications of fertility in women [20]. Conscientiousness was associated with more pregnancies [21] in a number of studies and with fewer pregnancies [22, 23] in some studies; this suggests that this dimension of personality may have positive and negative correlations with pregnancy. This difference may be due to the fact that personality traits in different studies were measured using different tools. One of the points leading to more conscientiousness was the dimension of conscientiousness [24], and these people had long-term plans for the future and paid more attention to interpersonal relationships [25]. These this feature can lead to planning for pregnancy and pregnant women.

The results of our study on perceived stress, with a mean of $26.98 \pm 7.56$, showed that mothers with stress were at a moderate level. It was also shown that the personality type of mothers could be a predictor of perceived stress. There was a positive and significant relationship between the personality type of neuroticism and openness to experience and perceived stress.

\section{Interpretation}

Based on the results of this study and previous studies, we found that there was a positive and significant relationship between neuroticism and stress, and those with this personality trait experienced more stressful events. In Nikrahan's et al. study entitled "Relationship between personality traits, stress coping styles and stress among pregnant women", it was shown that stress had a significant positive correlation with neuroticism [18]. Another study was conducted by Libera et al. in Poland, aimed at analysing the possible relationship between personality traits and level of stress experienced by women after premature labour. The obtained results showed that there was a positive relationship between the overall level of stress and its components with neuroticism [26]. In a study carried out by Lundell et al. in Sweden, with the aim of linking the personality traits associated with neuroticism and post-traumatic stress disorder, the obtained results showed that women who had symptoms of PTSD (post-traumatic stress disorder) and PTSS (posttraumatic stress symptom), after an abortion, had higher scores of personality traits associated with neuroticism [27]. This result was also consistent with those of Afshar et al., Canals, Rahnama Nehzami et al., Conrad and Stricker, as well as Kakavand and Da- 
mercheli [28-32]. According to the results of this study and previous research, we found that there was a positive and significant relationship between neuroticism and stress level. Eysenck believed that in individuals with neuroticism, the sympathetic nervous system showed an additional reaction, even to mild stresses, which results in chronic hypersensitivity. This mode almost led to an increased level of excitability in any crisis. In other words, individuals with neuroticism respond emotionally towards events that other people regard as insignificant [33].

Neuroticism encompasses a range of negative emotions, from anxiety, aggression, sadness and irritability, to depression, and can lead to many negative events and stressful events in life [34]. In fact, people who obtain a high score in neuroticism are prone to experiencing more negative emotions. Neuroticism increases the likelihood that a person will be exposed to stressful events. It also deals with processing and remembering negative life memories [18]. People with high neuroticism are prone to cognitive impairment and irrational thoughts and have a low ability to control their impulses, and they are much less able to cope with stress than others [35]. Consequently, based on the findings of this study, this conclusion is reasonable that there is a significant positive relationship between neuroticism and stress levels, because neuroticism is a factor associated with higher psychological vulnerability. In other words, if neuroticism is greater in a person, the psychological components of depression and psychological responses are more evident [36]. Neuroticism is often a reflection of the catastrophic sense of physical symptoms, which leads to more sensitivity and extreme concentration on individual stimuli [33]. Therefore, it is obvious that mothers with this personality trait are prone to fear and anxiety, and they perceive the slightest pain and impulse as a catastrophe.

The findings of another study showed that there was a significant and positive relationship between openness to experience and perceived stress. In a study by Williams et al., aimed at showing the relationship between openness to experience and stress in adults, the results showed that personality traits of openness to experience were associated with increased stress [37]. This conclusion was also consistent with the findings of the study by Rahnama Nehzami et al. [30]. With regard to the trait of openness to experience, people with this characteristic seemed to experience much more and deeper emotional situations, and the intensity of happiness and grief was more prominent in them. Individuals with higher scores on this scale expressed more excitement and might engage in multiple responsibilities at one time [30]. All of the above-mentioned psychological dimensions in mothers can potentially lead to stress through the physiological arousal of the nervous system and hormones. However, the relationship between these two needs to be further studied. One of the strengths of this study is that numerous studies have been conducted on stress, anxiety and health behaviours and the emergence of diseases [38-42], but there are few studies regarding the role of personality traits and health behaviours in pregnant women in Iran.

\section{Limitations of the study}

Among the problems with the implementation of this study due to the large number of questionnaires was some mothers' lack of willingness to answer the questions. However, while explaining the goals of the study, we either persuaded these mothers or excluded them from the study.

It is suggested that studies should be conducted with larger sample sizes in different cultures so that our findings can be more generalised. Interventional studies, such as the impact of teaching stress management skills to increase the ability of mothers to cope with stress, can also be useful. It is also suggested that the relationship between personality types and stress coping strategies in pregnant mothers, as well as the relationship between personality types and postpartum depression and planned and unplanned pregnancies, should also be investigated in future studies.

\section{Generalisability}

Considering the fact that this research was carried out in the three main hospitals of Shiraz and that the samples were randomly collected, generalisability can be cited, but due to limited research in this subject in Iran, more studies are needed in different cities.

\section{Conclusions}

The results of this study showed that perceived stress was related to some of the traits of mothers. The highest mean score and the highest frequency of personality type in this study were related to the personality trait of conscientiousness. The mothers had moderate perceived stress in this study, and the traits of neuroticism and openness to experience were related to the perceived stress of mothers. If it is accepted that every human being is an individual with unique characteristics, then identifying the individual differences between pregnant women and using valid instruments will help to the parturient mother during and after delivery. These results will be especially helpful to those who have a maternal support role during labour and delivery, such as doctors, midwives, nurses, spouses and trained attendant midwives (doulas) in pre-natal relationships with pregnant women under the supervision of a psychologist in the planning and performance of delivery.

Acknowledgements. This article is a part of Ms. Sahar Parvizi's thesis (project number: 15341), which was approved and sponsored by the Shiraz University of Medical Sciences. Thereby, the authors would like to thank the Shiraz University of Medical Sciences, Shiraz, Iran, as well as the Centre for Development of Clinical Research of Nemazee Hospital and Dr Nasrin Shokrpour for editorial assistance and statistical analysis.

Source of funding: This work was financed by the Shiraz University of Medical Sciences in Iran.

Conflicts of interest: The authors declare no conflicts of interest.

\section{References}

1. Karimi N, Rabiepoor S, Khalkhali HR, et al. Evaluation of anxiety and perceived stress in mothers undergoing amniocentesis. The J Urmia Nurs Midwifery Fac 2017; 15(4): 292-300.

2. Valiei S, Rezaei M, Rezaei K. The relationship between personality characteristics and nursing occupational stress. IJPN 2013; $1(3)$ : 27-34.

3. Sarani A, Azhari S, Yousefabadi SR, et al. The relationship between personality characteristics and coping with perceived stress in pregnant women referred to health centers in Mashhad. International Journal of Advanced Biotechnology Research 2016; 7(4): 105-134.

4. Hamilton JG, Lobel M. Types, patterns, and predictors of coping with stress during pregnancy: examination of the revised prenatal coping inventory in a diverse sample. J Psychosom Obstet Gynaecol 2008; 29(2): 97-104 
5. Sarani A, Azhari S, Yousefabadi SR, Mazlom SR, Aghamohammadian Sharbaf HRJIJoAB, Research. The relationship between personality characteristics and coping with perceived stress in pregnant women referred to health centers in Mashhad. 2016.

6. Toosi M, Akbarzadeh M, Zare N, et al. Effect of attachment training on anxiety and attachment behaviors of first-time mothers. Hayat 2011; 17(3): 69-79.

7. Nezami L, Azizi M. The predicting and incidence postpartum depression based on perceived stress during pregnancy in women of tabriz. Woman \& Study of Family 2015; 8(30): 113-125.

8. Akhgar M, Khalili M. Investigating the role of personality traits in anticipating stress coping styles in male student. Biannual Journal of Pouyesh in Educational and Consultation 2017; 4(6): 78-93.

9. Hejazi M. Comparison of personality characteristics and anxiety in pregnant women based on choosing the type of delivery. The Scientific Journal of Rehabilitation Medicine 2018; 7(1): 51-58.

10. Matinnia N, Haghighi M, Jahangard L, et al. Further evidence of psychological factors underlying choice of elective cesarean delivery (ECD) by primigravidae. Revista Brasileira de Psiquiatria 2018; 40(1): 83-88.

11. Harville EW, Madkour AS, Xie Y. Personality and adolescent pregnancy outcomes. JAN 2015; 71(1): 148-159.

12. Costa Jr PT, Terracciano A, McCrae RR. Gender differences in personality traits across cultures: robust and surprising findings. $J$ Pers Soc Psychol 2001; 81(2): 322-331.

13. Goldberg LR. A broad-bandwidth, public domain, personality inventory measuring the lower-level facets of several five-factor models. Personality Psychology in Europe 1999; 7(1): 7-28.

14. Ghorbani N, Framarz AG, Watson P. Philosophy, self-knowledge, and personality in Iranian teachers and students of philosophy. J Psychol 2005; 139(1): 81-95.

15. Ghorbani N, Watson PJ. Two facets of self-knowledge, the five-factor model, and promotions among Iranian managers. Soc Behav Personal 2004; 32(8): 769-776.

16. Cohen S, Kamarck T, Mermelstein R. A global measure of perceived stress. J Health Soc Behav 1983; 24(4): 385-396.

17. Saadat $S$, Asghari F, Jazayeri R. The relationship between academic self-efficacy with perceived stress, coping strategies and perceived social support among students of University of Guilan. IJME 2015; 15: 67-78.

18. Nikrahan GR, Kajbaf MB, Nouri A, et al. Assessment of the relationship between personality traits, coping styles with stress and stress level in pregnant women. The Iranian Journal of Obstetrics, Gynecology and Infertility 2011; 14(5): 51-59.

19. Varshoei Jaghargh M, Haji Alizadeh K. Determining the predictive factors of fear of childbirth based on personality traits, social support and emotional regulation among nulliparous pregnant mothers in Bandar Abbas. JNE 2017; 6(4): 38-47.

20. Berg V, Rotkirch A, Väisänen $\mathrm{H}$, et al. Personality is differentially associated with planned and non-planned pregnancies. J Res Pers 2013; 47(4): 296-305.

21. Dijkstra P, Barelds DP. Women's well-being: the role of individual differences. Scand J Psychol 2009; 50(4): 309-315.

22. Jokela M, Alvergne A, Pollet TV, et al. Reproductive behavior and personality traits of the Five Factor Model. Eur J Pers 2011; 25(6): 487-500.

23. Jokela M, Hintsa T, Hintsanen M, et al. Adult temperament and childbearing over the life course. Eur J Pers 2010; 24(2): 151-166.

24. Besharat M. Psychometric properties of the Persian form of resiliency scale. Research report. Tehran University; 2007.

25. Ahmetoglu G, Swami V, Chamorro-Premuzic T. The relationship between dimensions of love, personality, and relationship length. Arch Sex Behav 2010; 39(5): 1181-1190.

26. Libera A, Leszczynska-Gorzelak B, Oleszczuk J. Stress experienced by women after premature labor is conditioned by their personality. Ginekol Pol 2016; 87(5): 353-359.

27. Lundell IW, Poromaa IS, Ekselius L, et al. Neuroticism-related personality traits are associated with posttraumatic stress after abortion: findings from a Swedish multi-center cohort study. BMC Women's Health 2017; 17(1): 96, doi: 10.1186/s12905-017-0417-8.

28. Afshar H, Roohafza HR, Keshteli AH, et al. The association of personality traits and coping styles according to stress level. J Res Med Sci 2015; 20(4): 353-358.

29. Canals J, Esparó G, Fernández-Ballart JD. How anxiety levels during pregnancy are linked to personality dimensions and sociodemographic factors. Pers Individ Differ 2002; 33(2): 253-259.

30. Rahnama Nehzami N, Rezaei S, Jomehri F, et al. Personality characteristics and stress in peptic ulcer patients and healthy individuals: a comparative study considering sex differences. Daneshvar Medicine 2012; 19(99). Available from URL: http://daneshvarmed.shahed. ac.ir/article-1-547-en.html.

31. Conrad M, Stricker S. Personality and labor: a retrospective study of the relationship between personality traits and birthing experiences. J Reprod Infant Psyc 2018 ;36(1): 67-80.

32. Kakavand A, Damercheli N. The role of mediator of perceived stress in the relationship between personality traits and hypertension among the elderly. Journal of Aging Psychology 2017; 2(4): 271-279.

33. Peymannia B, Moosavi E. The comparison between conceived stress and personality traits, in people suffering from migraine and healthy people. Journal of Shahid Sadoughi University of Medical Sciences 2014; 22(2): 1069-1078.

34. Gustavsson JP, Jönsson EG, Linder J, et al. The HP5 inventory: definition and assessment of five health-relevant personality traits from a five-factor model perspective. Pers Indiv Differ 2003; 35(1): 69-89.

35. Bedin JE, Mattjie ML, Ferreira VRT, et al. The relationship between personality traits and stress levels in children. Psychology 2015; 6(06): 672-680.

36. Martínez MP, Sánchez Al, Miró E, et al. The relationship between the fear-avoidance model of pain and personality traits in fibromyalgia patients. J Clin Psychol Med Settings 2011; 18(4): 380-391.

37. Williams PG, Rau HK, Cribbet MR, et al. Openness to experience and stress regulation. J Res Pers 2009; 43(5): 777-784.

38. Salyer J, Flattery MP, Joyner PL, et al. Lifestyle and quality of life in long-term cardiac transplant recipients. J Heart Lung Transplant 2003; 22(3): 309-321.

39. de Jonge P, Denollet J, van Melle JP, et al. Associations of type-D personality and depression with somatic health in myocardial infarction patients. J Psychosom Res 2007; 63(5): 477-482

40. Akbarzadeh M, Rafiee B, Asadi N, et al. Comparative effect of attachment and relaxation training on perception of fetal movement and mother's anxiety in primiparous women: a randomized controlled study. Trends Med Res 2016; 11(2): 62-68.

41. Setodeh S, Pourahmad S, Akbarzadeh M. A study of the efficacy of fathers' attachment training on paternal-fetal attachment and parental anxiety. Fam Med Prim Care Rev 2017; 19(4): 393-398.

42. Branecka-Woźniak D, Karakiewicz B, Torbe A, et al. Evaluation of the occurrence of anxiety in pregnant women with regard to environmental conditions. Fam Med Prim Care Rev 2018; 20(4): 320-326. 
Tables: 4

Figures: 0

References: 42

Received: 3.04.2019

Reviewed: 21.04.2019

Accepted: 30.06.2019

Address for correspondence:

Marzieh Akbarzadeh, MSc

Maternal-Fetal Medicine Research Center

Department of Midwifery

School of Nursing and Midwifery

Shiraz University of Medical Sciences

Shiraz

Iran

Tel.: 0711-6474250

E-mail: akbarzadm@sums.ac.ir 